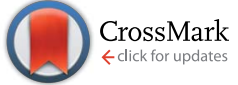

Cite this: RSC Adv., 2017, 7, 2766

Received 11th October 2016 Accepted 21st December 2016

DOI: 10.1039/c6ra25038f

www.rsc.org/advances

\title{
Single-molecule magnet behavior in a mononuclear dysprosium(III) complex with 1-methylimidazole $\uparrow$
}

\author{
Binling Yao, ${ }^{a}$ Bin Gu, ${ }^{a}$ Meihui Su, ${ }^{a}$ Guoliang Li, ${ }^{a}$ Yue Ma, ${ }^{* a}$ Licun Li, ${ }^{a}$ Qinglun Wang, ${ }^{a}$ \\ Peng Cheng ${ }^{a}$ and Xuan Zhang ${ }^{b}$
}

Three novel mononuclear lanthanide complexes coordinated with 1-methylimidazole [ $\mathrm{Ln}(\mathrm{hfac})_{3} \cdot(1-\mathrm{Melm})_{2}$ ] $(\mathrm{Ln}=\mathrm{Dy}(1), \mathrm{Tb}(2)$ and $\mathrm{Ho}(3), \mathrm{hfac}=$ hexafluoroacetylacetonate, 1-Melm = 1-methylimidazole) have been designed and characterized by single-crystal X-ray diffraction, luminescence and magnetic measurements. Studies indicate that the metal ions of all three mononuclear complexes adopt a slightly distorted $D_{4 d}\left[\mathrm{LnO}_{6} \mathrm{~N}_{2}\right]$ coordination environment, which is formed by two terminal 1-methylimidazole ligands and three bischelating $\mathrm{hfac}^{-}$anions. Frequency dependent out-of-phase signals were observed for complex 1 in dynamic magnetic susceptibility measurements, which indicates single-molecule magnetic behavior.

\section{Introduction}

Single molecular magnets (SMMs) have been an attractive research field owing to the memory effect exhibited by individual molecules, thus making them candidates for potential applications of high-density data storage technologies, quantum computing and single-spin manipulation. ${ }^{1}$ The large spin and strong intrinsic magneto-anisotropy of lanthanide ions (especially $\mathrm{Dy}^{\mathrm{III}}, \mathrm{Tb}^{\mathrm{III}}, \mathrm{Ho}^{\mathrm{III}}$ and $\mathrm{Er}^{\mathrm{III}}$ ) make them very attractive to construct SMMs of high spin-reversal barriers. ${ }^{2}$ In the past decade, many Ln-based SMMs have been reported, for example, mononuclear, ${ }^{3}$ dinuclear, ${ }^{4}$ trinuclear, ${ }^{5}$ tetranuclear ${ }^{6}$ pentanuclear $^{7}$ and polynuclear $^{8}$ lanthanide complexes. However, the challenge is to suppress the quantum tunneling of magnetization (QTM) in order to increase the anisotropy barrier, which depends mainly on the crystal field, intermolecular interactions as well as the hyperfine interactions. ${ }^{3 a, 8 a, 9}$ Our previous work showed that $\left[\mathrm{Dy}(\mathrm{hfac})_{3}(\mathrm{pz})_{2}\right](\mathrm{pz}$ $=$ pyrazole $^{10}$ was an SMM with a barrier of $28.32 \mathrm{~K}$, and how a small change of the ligand field or intermolecular Dy $\cdots$ Dy dipolar coupling affects the magnetic properties of Dy ${ }^{\mathrm{III}}$ SMMs. To further investigate the effect of inter-molecular interactions

${ }^{a}$ Department of Chemistry, Key Laboratory of Advanced Energy Materials Chemistry (MOE), TKL of Metal and Molecule Based Material Chemistry, Nankai University, Tianjin 300071, China. E-mail: maynk@nankai.edu.cn; Tel: +8622 23505063

${ }^{b}$ Department of Chemistry, Texas A\&M University, College Station, Texas 77842, USA $\dagger$ Electronic supplementary information (ESI) available: X-ray crystallographic data for complexes 1-3 in CIF format. Selected bond lengths and angles, figures of crystal structures, luminescence measurements, and magnetic measurements. CCDC 800739, 798521 and 1515832. For ESI and crystallographic data in CIF or other electronic format see DOI: 10.1039/c6ra25038f on SMM behavior, it is interesting to design a similar compound using 1-methylimidazole instead of pyrazole. The presence of the methyl group will affect the intermolecular Ln $\cdots$ Ln dipolar coupling of lanthanide complexes, which will give rise to subtle but intriguing changes of the magnetic properties. ${ }^{11,12}$

As mentioned above, by utilizing the 1-methylimidazole (1MeIm) ligand, three novel mononuclear lanthanide complexes $\left[\mathrm{Ln}(\mathrm{hfac})_{3} \cdot(1-\mathrm{MeIm})_{2}\right][\mathrm{Ln}=\mathrm{Dy}(\mathbf{1}), \mathrm{Tb}(2)$ and $\mathrm{Ho}(3)]$ have been obtained and characterized. Surprisingly, by using 1-methylimidazole instead of pyrazole to coordinate with Dy(hfac $)_{3}$ units in complex 1, it significantly increases the energy barrier of Dy(III) ion from 28.32 to $42.54 \mathrm{~K}$, with the change of ligand field symmetry from $D_{2 \mathrm{~d}}$ for Dy(III) ion to $D_{4 \mathrm{~d}}$. In addition, the expansion of intermolecular Dy-Dy distances from $8.87 \AA$ to $9.10 \AA$, as we expected, decreases the intermolecular Dy(III) coupling and suppresses QTM to some extent. Complex 1 represents an example of mononuclear lanthanide complexes displaying single-ion magnetic behavior.

Meanwhile, lanthanide compounds can exhibit highly efficient and long-lived luminescence with well-resolved multiline emissions in the UV-Vis. ${ }^{9 a, 13}$ So the luminescence spectra of complexes $\mathbf{1}$ and $\mathbf{2}$ are also investigated in the visible spectrum.

\section{Experimental}

\section{Materials and physical techniques}

All chemicals and reagents used in the syntheses were of analytical grade without further purification. $\mathrm{C}, \mathrm{H}, \mathrm{N}$ analyses were obtained on a Perking-Elmer elemental analyzer model 240. Fourier transform infrared spectroscopy was carried out in the range $400-4000 \mathrm{~cm}^{-1}$ on a Bruker TENOR 27 
Table 1 Crystallographic data and structure refinement for complexes 1, 2, 3

\begin{tabular}{|c|c|c|c|}
\hline & 1 & 2 & 3 \\
\hline Chemical formula & $\mathrm{C}_{23} \mathrm{H}_{15} \mathrm{DyF}_{18} \mathrm{~N}_{4} \mathrm{O}_{6}$ & $\mathrm{C}_{23} \mathrm{H}_{15} \mathrm{TbF}_{18} \mathrm{~N}_{4} \mathrm{O}_{6}$ & $\mathrm{C}_{23} \mathrm{H}_{15} \mathrm{HoF}_{18} \mathrm{~N}_{4} \mathrm{O}_{6}$ \\
\hline Formula weight & 947.89 & 944.32 & 950.32 \\
\hline Crystal system & Monoclinic & Monoclinic & Monoclinic \\
\hline Space group & $C 2 / c$ & $C 2 / c$ & $C 2 / c$ \\
\hline$a / \AA$ & $20.103(4)$ & $20.173(4)$ & $20.079(7)$ \\
\hline$\alpha /^{\circ}$ & 90 & 90 & 90 \\
\hline$\beta /^{\circ}$ & $113.88(3)$ & $113.82(3)$ & $113.89(3)$ \\
\hline$\gamma /{ }^{\circ}$ & 90 & 90 & 90 \\
\hline$V / \AA^{-3}$ & $3535.7(15)$ & $3557.6(15)$ & $3523(2)$ \\
\hline$Z$ & 4 & 4 & 4 \\
\hline$\rho /\left(\mathrm{g} \mathrm{cm}^{-3}\right)$ & 1.781 & 1.763 & 1.792 \\
\hline$R$ (int) & 0.0705 & 0.0547 & 0.0705 \\
\hline $\begin{array}{l}\text { Max./min. } \\
\text { transmission }\end{array}$ & $0.698 / 0.0 .644$ & $0.661 / 0.702$ & $0.717 / 0.751$ \\
\hline Goodness-of-fit on $F^{2}$ & 1.014 & 1.049 & 1.039 \\
\hline$R_{1}, \mathrm{w} R_{2}[I>2 \sigma(I)]$ & $0.0434 / 0.0987$ & $0.0428 / 0.1061$ & $0.0423 / 0.1035$ \\
\hline$R_{1}, \mathrm{w} R_{2}$ (all data) & $0.0500 / 0.1032$ & $0.0469 / 0.1108$ & $0.0468 / 0.1081$ \\
\hline
\end{tabular}

spectrophotometer using $\mathrm{KBr}$ pellets. Luminescence spectra and fluorescence lifetime studies were performed by using solid samples with an Edinburgh FLS-920P spectrophotometer. Inductively coupled plasma optical emission spectroscopy (ICPOES) was measured with central mental (Dy, Tb, and Ho) by Spectro-Blue. All magnetic data were measured on a SQUID MPMS XL-7 magnetometer using polycrystalline samples. Diamagnetic corrections of experimental magnetic susceptibility data are estimated from Pascal's constants. ${ }^{\mathbf{9 h}, \mathbf{1 4}}$

\section{Synthesis of $\left[\operatorname{Ln}(\mathrm{hfac})_{3} \cdot(1-\mathrm{MeIm})_{2}\right](\operatorname{Ln}=\operatorname{Dy}(1), \mathrm{Tb}(2), \mathrm{Ho}(3))$}

Dy(hfac $)_{3} \cdot 2 \mathrm{H}_{2} \mathrm{O}(0.05 \mathrm{mmol}, 0.041 \mathrm{~g})$ was suspended in $20 \mathrm{ml}$ of $n$-heptane and heated with stirring. After refluxing for about $2 \mathrm{~h}$ and cooling to $60{ }^{\circ} \mathrm{C}$, 1-methylimidazole ( $0.1 \mathrm{mmol}, 0.082 \mathrm{~g}$ ) in $\mathrm{CH}_{2} \mathrm{Cl}_{2}(5 \mathrm{ml})$ was added, and the mixture was stirred for 30 minutes. By cooling the solution to room temperature, the filtrate was slowly evaporated at $4{ }^{\circ} \mathrm{C}$. Colorless crystals of the product suitable for X-ray crystallography were obtained after a week. Complex 2 and $\mathbf{3}$ were synthesized following a similar procedure except that Dy(hfac $)_{3} \cdot 2 \mathrm{H}_{2} \mathrm{O}$ was substituted by $\mathrm{Tb}(\text { hfac })_{3} \cdot 2 \mathrm{H}_{2} \mathrm{O}$ and $\mathrm{Ho}(\text { hfac })_{3} \cdot 2 \mathrm{H}_{2} \mathrm{O}$ respectively. Yield: $21.8 \mathrm{mg}, 45.9 \%$, based on Dy. Anal. calcd (1): $\mathrm{C}_{23} \mathrm{H}_{15} \mathrm{DyF}_{18} \mathrm{~N}_{4} \mathrm{O}_{6}$ : C, 29.14; H, 1.60; N, 5.91. Found (1): C, 28.89; H, 1.60; N, 5.95\%. ICP-OES anal. Found: Dy, 17.14; calcd. Found: 17.45; IR (KBr, $\nu /$ $\left.\mathrm{cm}^{-1}\right):$ 3150(w), 1645(vs), 1535(w), 1485(s), 1248(s), 1189(s), 1138(vs), 1096(s), 935(w), 800(s), 757(w), 664(vs), 580(s). Yield: $21.8 \mathrm{mg}, 46.2 \%$, based on Tb. Anal. calcd (2): $\mathrm{C}_{23} \mathrm{H}_{15} \mathrm{TbF}_{18} \mathrm{~N}_{4} \mathrm{O}_{6}$ : C, 29.21; H, 1.59; N, 5.95\%. Found (2): C, 28.85; H, 1.61; N, 5.94\% ICP-OES anal. Found: Tb, 16.83; calcd. Found: Tb, 16.51; IR (KBr, $\left./ \mathrm{cm}^{-1}\right)$ : 3152(w), 1645(vs), 1535(w), 1468(s), 1256(s), 1189(s), 1138(vs), 1096(s), 935(w), 800(s), 757(w), 656(vs), 582(s) anal. calcd (3): $\mathrm{C}_{23} \mathrm{H}_{15} \mathrm{HoF}_{18} \mathrm{~N}_{4} \mathrm{O}_{6}$ : C, 29.07; H, 1.59; N, 5.90. Yield: $21.2 \mathrm{mg}, 44.6 \%$, based on Ho. Found (3): C, 29.13; H, 1.63; N, 5.88\%. ICP-OES Anal. Found: Ho, 17.36; calcd. Found: Ho, 17.75; IR (KBr, $\left.\nu / \mathrm{cm}^{-1}\right)$ : 3150(w), 1644(vs), 1535(w), 1476(s), 1255(s), 1189(s), 1137(vs), 1097(s), 944(w), 801(s), 741(w), 655(vs), $580(\mathrm{~s}) .{ }^{15}$

\section{Crystal structure determination and refinement}

Suitable crystals were selected and mounted on a Bruker SMART 1000 diffractometer with graphite monochromated Mo $\mathrm{K} \alpha$ radiation $(\lambda=0.71073 \AA)$ at $113 \mathrm{~K}$ for 1,2 and 3. Lorentzpolarization correction was applied to the data. The structures were solved by direct methods using SHELXS-2014 ${ }^{16}$ program and refinements on $F^{2}$ were performed using SHELXL-2014 by full-matrix least-squares procedure with anisotropic thermal parameters for all non-hydrogen atoms. Hydrogen atoms were added theoretically and refined with riding model position parameters and isotropically refined crystal data and details of structural determination and refinement are summarized in Table 1 and the selected bond lengths and angles have been provided in the ESI, Tables S1-S3.†

\section{Results and discussion}

\section{Crystal structures}

Compared with the previously reported $\left[\mathrm{Dy}(\mathrm{hfac})_{3} \cdot(\mathrm{pz})_{2}\right]$, complex 1 has a similar mononuclear structure and is synthesized by substituting two $\mathrm{H}_{2} \mathrm{O}$ molecules by two 1-methylimidazole ligands in a Dy(hfac $)_{3} \cdot 2 \mathrm{H}_{2} \mathrm{O}$ salt. It crystalizes as a symmetrical mononuclear compound [Dy(hfac $\left.)_{3} \cdot(1-\mathrm{MeIm})_{2}\right]$ in monoclinic $C 2 / c$ space group (Fig. 1 ). The Dy ${ }^{\mathrm{III}}$ core is also 

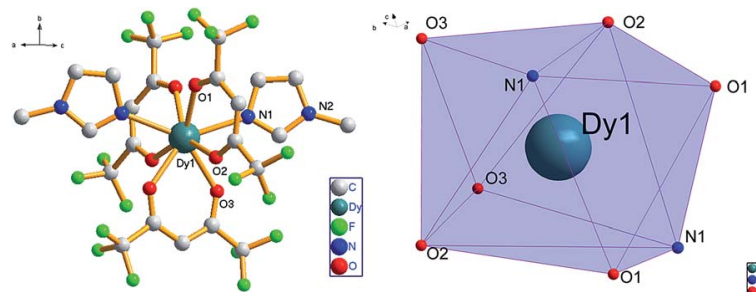

Fig. 1 Perspective view of complex [Dy $\left.(\mathrm{hfac})_{3} \cdot(1-\mathrm{Melm})_{2}\right](\mathrm{H}$ atoms were all omitted for clarity, left) and the coordination polyhedron of the Dy ${ }^{\prime \prime \prime}$ ions (right).

eight-coordinated in a $\left[\mathrm{DyO}_{6} \mathrm{~N}_{2}\right]$ environment with Dy-O bond lengths in the range of 2.346(4)-2.358(4) $\AA$, which is shorter than that of Dy-N (2.467(4) $\AA$ ). The angles of O-Dy-O is ranging from 71.2 to $145.1^{\circ}$, the bond angles $\mathrm{O}-\mathrm{Dy}-\mathrm{N}$ is ranging from 73.6 to $143.8^{\circ}$, and the angle of $\mathrm{N}(1)^{1}-\mathrm{Dy}(1)-\mathrm{N}(1)$ is $141.7^{\circ}$. The $\left[\mathrm{DyO}_{6} \mathrm{~N}_{2}\right]$ geometry is studied using the SHAPE software ${ }^{17}$ to obtain the minimal deviation parameter $S$ of 0.396 for $D_{4 \mathrm{~d}}$ symmetry as shown in Table 2, rather than $D_{2 \mathrm{~d}}$ as in $\left[\mathrm{Dy}(\mathrm{hfac})_{3} \cdot(\mathrm{pz})_{2}\right]$. The shortest intermolecular Dy $\cdots$ Dy separation distance of $9.098(8) \AA$ is larger than that of $\left[\mathrm{Dy}(\mathrm{hfac})_{3}(\mathrm{pz})_{2}\right]$ $(8.87 \AA)$. The packing diagram of the compound $\mathbf{1}$ is given in the ESI, Fig. S1, $\dagger$ which shows no inter- and intramolecular $\pi-\pi$ interaction. Hydrogen bonding interactions between the molecules were not found in the complex 1.

The structures of complex 2 and 3 consist of similar mononuclear units as those in complex $\mathbf{1}$ with only small differences in the bond lengths and angles. Their molecular structures, $D_{4 \mathrm{~d}^{-}}$ symmetry polyhedrons and packing diagrams are given in the ESI, Fig. S2-S5.†

\section{Luminescence properties}

Fig. 2 shows the emission spectrum of the $\mathrm{Dy}^{\mathrm{III}}$ and $\mathrm{Tb}^{\mathrm{III}}$ complexes recorded at room temperature under irradiation of UV light at 350 and $347 \mathrm{~nm}$, respectively. Well-resolved multiline emissions of Dy ${ }^{\text {III }}$ ion were observed around 480, 573 and $661 \mathrm{~nm}$, which can be attributed to ${ }^{4} \mathrm{~F}_{9 / 2} \rightarrow{ }^{6} \mathrm{H}_{J}$ with $J=15 / 2,13 /$ 2 and 11/2, respectively (Fig. 2a). ${ }^{13 b, d}$ Four characteristic peaks of the $\mathrm{Tb}^{\mathrm{III}}$ complex shown in Fig. $2 \mathrm{~b}$ are attributed to the metalcentered ${ }^{5} \mathrm{D}_{4}$ excited state to the ${ }^{7} \mathrm{~F}_{J}$ ground-state multiplet. Maximum emission peaks at 489, 544, 587 and $621 \mathrm{~nm}$, were observed for the $J=3,4,5$ and 6 transitions, respectively. ${ }^{13 k}$

The decay lifetime curves reveal single-exponential mode with the lifetimes of $\tau_{1}=0.4549 \mu \mathrm{s}(100 \%)$ for 1 , while doubleexponential mode was observed for 2 , giving lifetime values $(17.06 \mu \mathrm{s}(31.66 \%)$ and $237.0 \mu \mathrm{s}(68.34 \%))$, as determined by

Table 2 The minimal deviation parameter $S$ for complex 1, 2, 3 of $\mathrm{Ln}^{\prime \prime \prime}$ ion geometry analysis by using the SHAPE software

\begin{tabular}{llll}
\hline $\mathrm{Ln}^{\mathrm{III}}$ & $D_{2 \mathrm{~d}^{-}} \mathrm{DD}$ & $C_{2 \mathrm{v}^{-}} \mathrm{TP}$ & $D_{4 \mathrm{~d}^{-}} \mathrm{SAP}$ \\
\hline $\mathrm{Dy}^{\mathrm{III}}$ & 1.397 & 2.734 & 0.396 \\
$\mathrm{~Tb}^{\mathrm{III}}$ & 1.457 & 1.439 & 1.971 \\
$\mathrm{Ho}^{\mathrm{III}}$ & 1.959 & 0.359 & 0.380
\end{tabular}
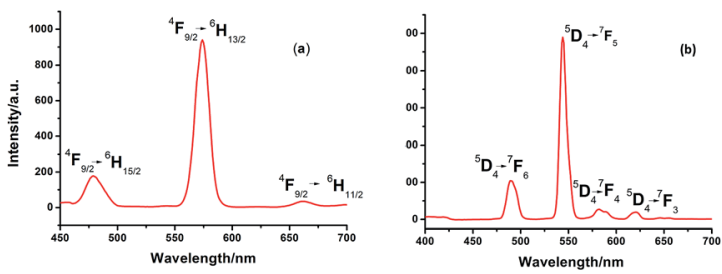

Fig. 2 The luminescence spectra of 1 (a) and 2 (b) in the solid state at room temperature.

monitoring the ${ }^{5} \mathrm{D}_{4} \rightarrow{ }^{7} \mathrm{~F}_{5}$ transition (Fig. S6 $\dagger$ ). Moreover, for complex 2, the fluorescence lifetime is a little higher than that of $\left[\mathrm{Tb}(\mathrm{hfac})_{3}(\mathrm{pz})_{2}\right]^{10}(77 \mu \mathrm{s})$, showing that the ancillary ligand of 1-methylimidazole has an antenna effect on the luminescence of the $\mathrm{Tb}^{\mathrm{III}}$ complex, with the adding of methyl to give more electron density to the aromatic ring.

\section{Magnetic properties}

Static magnetic properties of 1 . Magnetic susceptibility measurement of 1 was carried out under an external direct current (dc) magnetic field of $0.1 \mathrm{~T}$ at $2-300 \mathrm{~K}$. At $300 \mathrm{~K}$, the $\chi_{\mathrm{M}} T$ value of $14.60 \mathrm{~cm}^{3} \mathrm{~K} \mathrm{~mol}^{-1}$ were obtained, which is slightly higher than the expected value of $14.17 \mathrm{~cm}^{3} \mathrm{~K} \mathrm{~mol}^{-1}$ for one uncoupled Dy ${ }^{\mathrm{III}}$ cation (Dy $\mathrm{Dy}^{\mathrm{III}}: S=5 / 2, L=5,{ }^{6} \mathrm{H}_{15 / 2}, g=4 / 3$ ). The $\chi_{\mathrm{M}} T$ value keeps roughly constant from $300 \mathrm{~K}$ to $50 \mathrm{~K}$ but decreases more and more rapidly as temperature drops from 50 $\mathrm{K}$ and reaches a minimum value of $13.13 \mathrm{~cm}^{3} \mathrm{~K} \mathrm{~mol}^{-1}$ at $2 \mathrm{~K}$ (Fig. 3), which probably results from the progressive depopulation of the Dy ${ }^{\text {III }}$ stark sublevels and/or intermolecular interactions. Reduced magnetization data for complex $\mathbf{1}$ was determined at different temperatures (inset of Fig. 3). The magnetization values show poor superposition even at the highest available fields. Moreover, the maximum value of 8.86 $\mathrm{N} \beta$ is considerably lower than the expected value, which indicates the presence of a significant magnetic anisotropy and/or low-lying excited states..$^{3 i, 9 h, 18}$

Dynamic magnetic properties of 1 . The frequency- and temperature-dependent alternating current (ac) susceptibilities for 1 were obtained under zero-dc field (Fig. 4 and S7 $†$ ). With the increasing temperature the peaks of the $\chi^{\prime \prime}{ }_{M}$ data move to higher frequency, which reveals the typical features associated with the

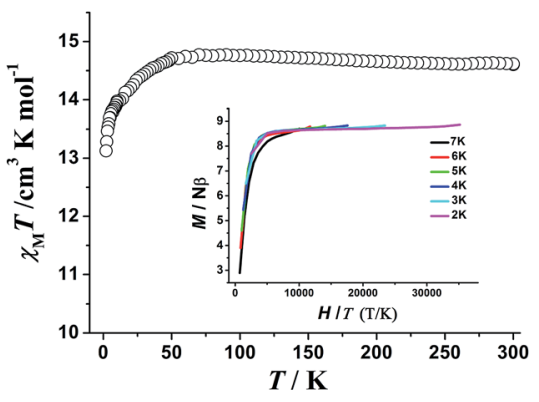

Fig. 3 Temperature dependency of $\chi_{M} T$ in the range of $2-300 \mathrm{~K}$ in 0.1 $\mathrm{T}$ for 1. Inset: $M$ vs. H/T plot measured in different fields below $7 \mathrm{~T}$. 

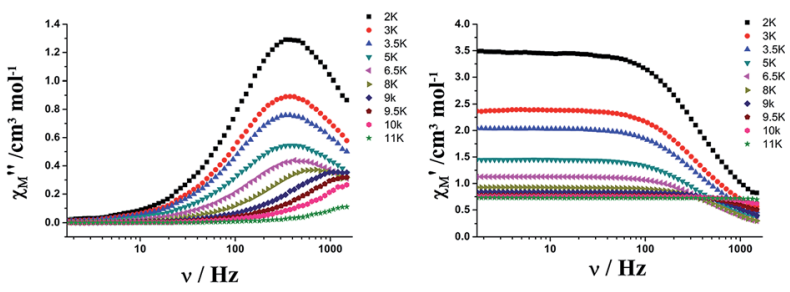

Fig. 4 Frequency dependence of the in-phase (left) and out-of-phase (right) ac susceptibility of 1 below $11 \mathrm{~K}$, under zero-dc field.

SMM behavior. To further ensure the complex 1 is a SMM but not a spin-glass $(0.01<\phi<0.08)$, the indicative parameter of spin disorder $\phi$ of 0.21 was obtained based on the data of the temperature dependencies of $\chi_{\mathrm{M}}^{\prime}$, using Mydosh's formula in eqn (1). ${ }^{19}$

$$
\phi=\left(\Delta T_{\mathrm{p}} / T_{\mathrm{p}}\right) / \Delta(\log \omega)
$$

The magnetization relaxation time in the form of $\ln \tau$ derived from the frequency-dependence measurements is plotted as a function of $1 / T$ between 2 and $11 \mathrm{~K}$ (Fig. 5). Above $7.7 \mathrm{~K}$, the relaxation follows a thermally activated process permitting the estimation of an energy barrier of $42.54 \mathrm{~K}$ with a pre-exponential factor $\left(\tau_{0}\right)$ of $1.13 \times 10^{-6} \mathrm{~s}$ based on the Arrhenius law, which is consistent with the expected $\tau_{0}$ of $10^{-6}$ to $10^{-11}$ for a SMM..$^{3-i}$ At lower temperatures a gradual crossover to a temperatureindependent regime is observed and below about $3.5 \mathrm{~K}$, a dominant quantum regime with a $\tau$ value of $0.0004 \mathrm{~s}$ explains the absence of $M v s$. $H$ hysteresis effect at $2 \mathrm{~K}$ (Fig. S8†), which is likely due to the hyperfine coupling and dipolar spin-spin interactions of the metal cations. As a result, fast quantum tunneling of magnetization was observed.

Cole-cole plots (Fig. 6) in the temperature range of $2-10 \mathrm{~K}$ with the form of $\chi^{\prime \prime}{ }_{\mathrm{M}}$ vs. $\chi_{\mathrm{M}}^{\prime}$, which can be well fitted by the generalized Debye model, ${ }^{\mathbf{2 0 a}, \boldsymbol{b}}$ exhibit good semicircle shapes and small distribution parameters $\alpha$ have been obtained (Table $\mathrm{S} 4 \dagger$ ). All of these magnetic parameters reveal a single relaxation process in complex 1. ${ }^{20 c, d}$ All the magnetic analyses as discussed

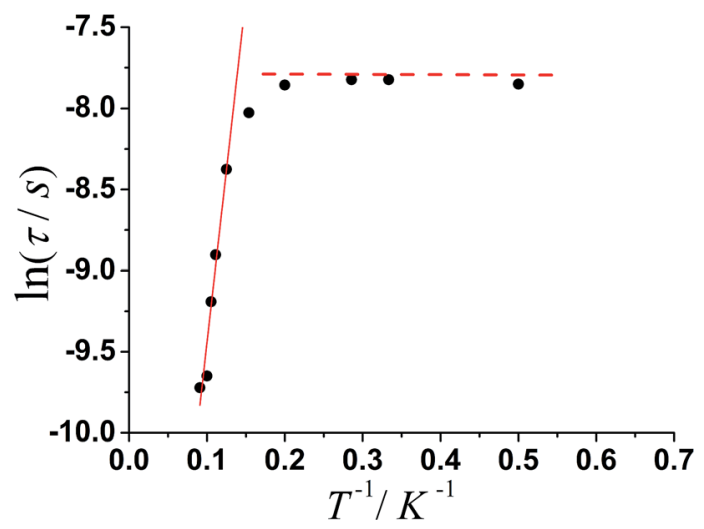

Fig. 5 Magnetization relaxation time, In $\tau$ vs. $T^{-1}$ plot for 1 under zerodc field. The solid line is with the fitting to the Arrhenius law.

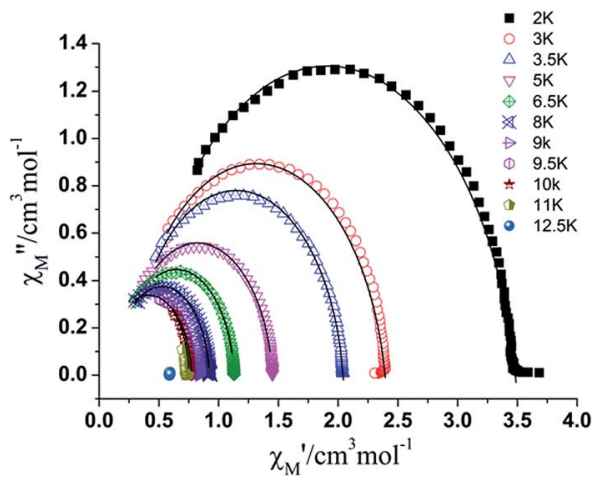

Fig. 6 Cole-cole plots measured at $2-11 \mathrm{~K}$ in zero-dc field.

above support the SMM nature of the mononuclear Dy complex 1. Compared with $\left[\mathrm{Dy}(\mathrm{hfac})_{3}(\mathrm{pz})_{2}\right]^{10}$, the use of 1-methylimidazole instead of pyrazole to coordinate with Dy(hfac) $)_{3}$ units leads to the improvement of the ligand field (from $D_{2 \mathrm{~d}}$ for lanthanide ion to $D_{4 \mathrm{~d}}$ ), and further enlarges the energy barrier of Dy ion from 28.32 to $42.54 \mathrm{~K}$. The higher symmetric coordination environments (as an example $\left(D_{4 \mathrm{~d}}\right)^{3 a, g, 21}$ ) reduce the admixing of states on opposite sides of the barrier and successfully suppress QTM, which proved the conclusion already obtained by Tong et al. that SIMs with the five symmetries $\left(C_{\infty \mathrm{v}}, D_{\infty \mathrm{h}}, S_{8}\left(I_{4}\right), D_{5 \mathrm{~h}}\right.$, and $\left.D_{4 \mathrm{~d}}\right)$ usually showing higher energy barriers. ${ }^{3 \boldsymbol{a}, \boldsymbol{c}, \boldsymbol{e}, \boldsymbol{h}, \mathbf{2 2}}$ And the intermolecular Dy-Dy distance changes from $8.87 \AA$ to $9.10 \AA$, also decreases the intermolecular Dy ions dipolar coupling then minimize the QTM to some extent.

Static magnetic properties for 2 and 3. As depicted in Fig. 7 and 8 , the temperature dependence of magnetic susceptibilities for 2 and 3 are also studied over the range from 300 to $2 \mathrm{~K}$. At room temperature, the $\chi_{\mathrm{M}} T$ values are 11.85 and $13.85 \mathrm{~cm}^{3} \mathrm{~K}$ $\mathrm{mol}^{-1}$ for 2 and 3, respectively. The value of complex 2 is in good agreement with the expected value of 11.81 for one uncoupled $\mathrm{Tb}^{\mathrm{III}}$ ion with ${ }^{7} \mathrm{~F}_{6}$ ground state, but 3 is slightly lower than 14.06 $\mathrm{cm}^{3} \mathrm{~K} \mathrm{~mol}^{-1}$ for one uncoupled $\mathrm{Ho}^{\mathrm{III}}$ ion with ${ }^{5} \mathrm{I}_{8}$ ground state. Upon cooling, the $\chi_{\mathrm{M}} T$ value of 2 goes down slowly and reaches a minimum of $11.57 \mathrm{~cm}^{3} \mathrm{~K} \mathrm{~mol}^{-1}$ at $77 \mathrm{~K}$, then gradually rises to a maximum of 11.75 at $53.4 \mathrm{~K}$ and further declines more and more rapidly to $10.13 \mathrm{~cm}^{3} \mathrm{~K} \mathrm{~mol}^{-1}$ at $2 \mathrm{~K}$. However, the $\chi_{\mathrm{M}} T$

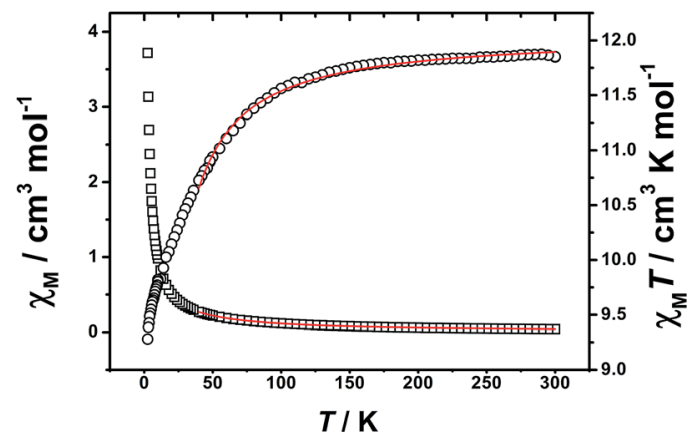

Fig. 7 Temperature dependence of $\chi_{M}$ and $\chi_{M}{ }^{T}$ product in the range of $2-300 \mathrm{~K}$ in $0.1 \mathrm{~T}$ for 2 . 


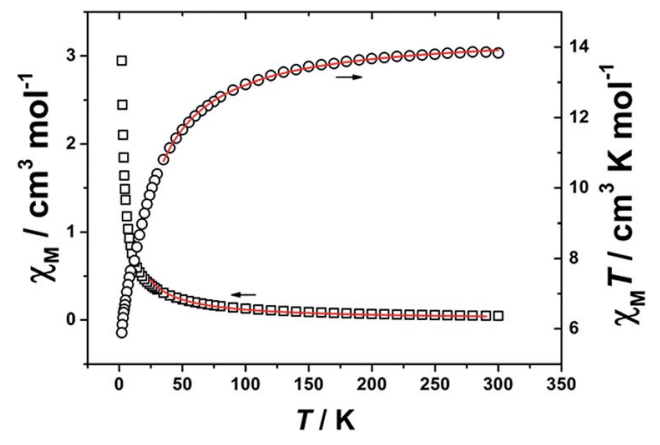

Fig. 8 Temperature dependence of $\chi_{M}$ and $\chi_{M} T$ product in the range of $2-300 \mathrm{~K}$ in $0.1 \mathrm{~T}$ for 3

value for 3 gradually deceases over the temperature range 120 $300 \mathrm{~K}$ and further goes down dramatically to reach a minimum value of $5.89 \mathrm{~cm}^{3} \mathrm{~K} \mathrm{~mol}^{-1}$ at $2 \mathrm{~K}$. To obtain a rough quantitative estimation of the magnetic interaction between paramagnetic species ${ }^{23}$ the magnetic data of 2 and $\mathbf{3}$ can be analyzed by the approximate model, ${ }^{11}$ which is given in the ESI, eqn (2)-(4) $\dagger$ using an anisotropic exchange Hamiltonian $H=\Delta J_{\mathrm{z}}^{2}$. The intermolecular interactions were considered by the term $z j^{\prime}$.

The best fitting results yielded, $z j^{\prime}=0.106 \mathrm{~cm}^{-1}(\Delta=0.526$ $\mathrm{cm}^{-1}$ ) with the $g$-factor of 1.516 for $\mathrm{Tb}$ complex, and $z j^{\prime}=-0.230$ $\mathrm{cm}^{-1}\left(\Delta=-0.154 \mathrm{~cm}^{-1}\right)$ with the $g$-factor of 1.267 for Ho complex. The small value of $z j^{\prime}$ is indicative of the very weak magnetic interaction between $\mathrm{Ln}^{\mathrm{III}}$ ions in $\mathbf{2}$ and $\mathbf{3}$.

Variable temperature ac susceptibility data for complexes 2 and 3 are also collected, which are given in the ESI, Fig. S9 and S10. $\dagger$ No frequency-dependent signals of imaginary component $\chi_{M}^{\prime \prime}$ have been observed for two complexes even at $2 \mathrm{~K}$. That might be due to the $\mathrm{Tb}$ and Ho ions spin states are more sensitive to crystal-field, which usually give $\mathrm{Tb}$ and Ho ions very small $J$ grand state and/or QTM, to induce their complexes have too small energy barrier to prevent the inversion of the spin.

\section{Conclusion}

Using 1-methylimidazole ligand in association with $\mathrm{Dy}^{\mathrm{III}}$, we successfully synthesized a symmetrical mononuclear complex of $\left[\mathrm{Dy}(\mathrm{hfac})_{3} \cdot(1-\mathrm{MeIm})_{2}\right]$, which exhibits slow relaxation of magnetization considered as one of the examples of a SMM as well as the Dy ${ }^{\mathrm{III}}$ characteristic emission at room temperature. The change of ligand field symmetry from $D_{2 \mathrm{~d}}$ for lanthanide ion to $D_{4 \mathrm{~d}}$ resulted in a larger energy barrier of Dy ion from 28.32 to $42.54 \mathrm{~K}$ in complex 1 where 1-methylimidazole was coordinated, as compared to $\left[\mathrm{Dy}(\mathrm{hfac})_{3}(\mathrm{pz})_{2}\right]$. The higher symmetry coordination environments reduce the admixing of states on opposite sides of the barrier, which controls QTM by tuning the local symmetry of the metal centers. The expansion of intermolecular Dy-Dy distance from $8.87 \AA$ to $9.10 \AA$ as we expected probably decreases the intermolecular Dy ions dipolar coupling and suppresses QTM effectively as well. It is obvious that the variation in ligands leads to the change of ligand field and magnetic interaction, which affect the magnetic properties of lanthanide complexes. This proves to be a powerful approach to understand how ligand field symmetry and magnetic interactions affect the SMM behaviors of lanthanide-based systems.

\section{Acknowledgements}

This work was supported by the National Natural Science Foundation of China 21471084, 21471083, 21371104. National Undergraduates Innovating Experimentation Project 201410055097.

\section{Notes and references}

1 (a) R. J. Blagg, L. Ungur, F. Tuna, J. Speak, P. Comar, D. Collison, W. Wernsdorfer, E. J. L. Mclnnes, L. F. Chibotaru and R. E. P. Winpenny, Nat. Chem., 2013, 5, 673-678; (b) L. Bogani and W. Wernsdorfer, Nat. Mater., 2008, 7, 179-186; (c) R. A. Layfield, Organometallics, 2014, 33, 1084-1099; (d) A. Cornia, M. Mannini, P. Sainctavit and R. Sessoli, Chem. Soc. Rev., 2011, 40, 3076-3091; (e) M. Urdampilleta, S. Klyatskaya, J.-P. Cleuziou, M. Ruben and W. Wernsdorfer, Nat. Mater., 2011, 10, 502-506; (f) D. N. Woodruff, R. E. P. Winpenny and R. A. Layfield, Chem. Rev., 2013, 113, 5110-5148.

2 (a) J. L. Liu, J. Y. Wu, G. Z. Huang, Y. C. Chen, J. H. Jia, L. Ungur, L. F. Chibotaru, X. M. Chen and M. L. Tong, Sci. Rep., 2015, 5, 16621; (b) R. J. Blagg, L. Ungur, F. Tuna, J. Speak, P. Comar, D. Collison, W. Wernsdorfer, E. J. L. McInnes, L. F. Chibotaru and R. E. P. Winpenny, Nat. Chem., 2013, 5, 673-678; (c) S. D. Jiang, B. W. Wang, H. L. Sun, Z. M. Wang and S. Gao, J. Am. Chem. Soc., 2011, 133, 4730-4733; (d) J. L. Liu, Y. C. Chen, Y. Z. Zheng, W. Q. Lin, L. Ungur, W. Wernsdorfer, L. F. Chibotaru and M. L. Tong, Chem. Sci., 2013, 4, 3310-3316; (e) J. Liu, Y. C. Chen, J. L. Liu, V. Vieru, L. Ungur, J. H. Jia, L. F. Chibotaru, Y. Lan, W. Wernsdorfer, S. Gao, X. M. Chen and M. L. Tong, J. Am. Chem. Soc., 2016, 138, 5441-5450.

3 (a) N. Ishikawa, M. Sugita, T. Ishikawa, S.-y. Koshihara and Y. Kaizu, J. Am. Chem. Soc., 2003, 125, 8694-8695; (b) N. Ishikawa, M. Sugita and W. Wernsdorfer, Angew. Chem., Int. Ed., 2005, 44, 2931-2935; (c) M. A. AlDamen, J. M. Clemente-Juan, E. Coronado, C. Martí-Gastaldo and A. Gaita-Ariño, J. Am. Chem. Soc., 2008, 130, 8874-8875; (d) F. Branzoli, P. Carretta, M. Filibian, G. Zoppellaro, M. J. Graf, J. R. Galan-Mascaros, O. Fuhr, S. Brink and M. J. Ruben, J. Am. Chem. Soc., 2009, 131, 4387-4396; (e) Y.-C. Chen, J.-L. Liu, L. Ungur, J. Liu, Q.-W. Li, L.-F. Wang, Z.-P. Ni, L. F. Chibotaru, X.-M. Chen and M.-L. Tong, J. Am. Chem. Soc., 2016, 138, 2829-2837; (f) M. Gonidec, F. Luis, À. Vílchez, J. Esquena, D. B. Amabilino and J. Veciana, Angew. Chem., Int. Ed., 2010, 49, 1623-1626; (g) G. J. Chen, C. Y. Gao, J. L. Tian, J. K. Tang, W. Gu, X. Liu, S. P. Yan, D. Z. Liao and P. Cheng, Dalton Trans., 2011, 40, 55795583; (h) S. D. Jiang, B. W. Wang, G. Su, Z. M. Wang and S. Gao, Angew. Chem., Int. Ed., 2010, 49, 7448-7451; (i) K. Bernot, J. Luzon, L. Bogani, M. Etienne, C. Sangregorio, 
M. Shanmugam, A. Caneschi, R. Sessoli and D. Gatteschi, J. Am. Chem. Soc., 2009, 131, 5573-5579.

4 (a) J. Long, F. Habib, P. H. Lin, I. Korobkov, G. Enright, L. Ungur, W. Wernsdorfer, L. F. Chibotaru and M. Murugesu, J. Am. Chem. Soc., 2011, 133, 5319-5328; (b) C. Wang, S. Y. Lin, J. Wu, S. W. Yuan and J. Tang, Dalton Trans., 2015, 44, 4648-4654; (c) L. F. Chibotaru, L. Ungur and A. Soncini, Angew. Chem., Int. Ed., 2008, 47, 4126-4129; (d) J. Luzon, K. Bernot, I. J. Hewitt, C. E. Anson, A. K. Powell and R. Sessoli, Phys. Rev. Lett., 2008, 100, 247205; (e) F. Habib, P. H. Lin, J. Long, I. Korobkov, W. Wernsdorfer and M. Murugesu, J. Am. Chem. Soc., 2011, 133, 8830-8833.

5 (a) J. K. Tang, I. Hewitt, N. T. Madhu, G. Chastanet, W. Wernsdorfer, C. E. Anson, C. Benelli, R. Sessoli and A. K. Powell, Angew. Chem., Int. Ed., 2006, 45, 1729-1733; (b) S. Xue, X. H. Chen, L. Zhao, Y. N. Guo and J. K. Tang, Inorg. Chem., 2012, 51, 13264-13270; (c) I. J. Hewitt, Y. Lan, C. E. Anson, J. Luzon, R. Sessoli and A. K. Powell, Chem. Commun., 2009, 6765-6767.

6 (a) Y. N. Guo, G. F. Xu, P. Gamez, L. Zhao, S. Y. Lin, R. Deng, J. K. Tang and H. J. Zhang, J. Am. Chem. Soc., 2010, 132, 85388539; (b) B. H. Koo, K. S. Lim, D. W. Ryu, W. R. Lee, E. K. Koh and C. S. Hong, Chem. Commun., 2012, 48, 2519-2521; (c) P. H. Lin, T. J. Burchell, L. Ungur, L. F. Chibotaru, W. Wernsdorfer and M. Murugesu, Angew. Chem., Int. Ed., 2009, 48, 9489-9492; (d) P. H. Lin, I. Korobkov, W. Wernsdorfer, L. Ungur, L. F. Chibotaru and M. Murugesu, Eur. J. Inorg. Chem., 2011, 1535-1539; (e) M. U. Anwar, L. K. Thompson, L. N. Dawe, F. Habib and M. Murugesu, Chem. Commun., 2012, 48, 4576-4578; (f) V. Chandrasekhar, S. Das, A. Dey, S. Hossain and J.-P. Sutter, Inorg. Chem., 2013, 52, 11956-11965.

7 (a) R. J. Blagg, C. A. Muryn, E. J. L. McInnes, F. Tuna and R. E. P. Winpenny, Angew. Chem., Int. Ed., 2011, 50, 65306533; (b) R. J. Blagg, F. Tuna, E. J. L. McInnes and R. E. P. Winpenny, Chem. Commun., 2011, 47, 10587-10589. 8 (a) Y. N. Guo, X. H. Chen, S. Xue and J. K. Tang, Inorg. Chem., 2012, 51, 4035-4042; (b) H. Tian, M. Wang, L. Zhao, Y. N. Guo, Y. Guo, J. K. Tang and Z. Liu, Chem.-Eur. J., 2012, 18, 442-445; (c) H. Tian, Y. N. Guo, L. Zhao, J. K. Tang and Z. Liu, Inorg. Chem., 2011, 50, 8688-8690; (d) J. W. Sharples, Y. Zheng, F. Tuna, E. J. L. McInnes and D. Collison, Chem. Commun., 2011, 47, 7650-7652; (e) H. Tian, L. Zhao, Y. N. Guo, Y. Guo, J. K. Tang and Z. Liu, Chem. Commun., 2012, 48, 708-710; $(f)$ Y. L. Miao, J. L. Liu, J. D. Leng, Z. J. Lina and M. L. Tong, CrystEngComm, 2011, 13, 3345-3348; (g) Y. Z. Zheng, Y. Lan, W. Wernsdorfer, C. E. Anson and A. K. Powell, Chem.-Eur. J., 2009, 15, 12566-15270; (h) I. J. Hewitt, J. K. Tang, N. T. Madhu, C. E. Anson, Y. Lan, J. Luzon, M. Etienne, R. Sessoli and A. K. Powell, Angew. Chem., Int. Ed., 2010, 49, 6352-6356.

9 (a) G. Cucinotta, M. Perfetti, J. Luzon, M. Etienne, P.-E. Car, A. Caneschi, G. Calvez, K. Bernot and R. Sessoli, Angew. Chem., Int. Ed., 2012, 51, 1606-1610; (b) M. J. MartínezPérez, S. Cardona-Serra, C. Schlegel, F. Moro, P. J. Alonso, H. Prima-García, J. M. Clemente-Juan, M. Evangelisti,
A. Gaita-Ariño, J. Sesé, J. van Slageren, E. Coronado and F. Luis, Phys. Rev. Lett., 2012, 108, 247213; (c) F. Habib, J. Long, P. H. Lin, I. Korobkov, L. Ungur, W. Wernsdorfer, L. F. Chibotaru and M. Murugesu, Chem. Sci., 2012, 3, 2158-2164; (d) U. J. Williams, B. D. Mahoney, P. T. DeGregorio, P. J. Carroll, E. Nakamaru-Ogiso, J. M. Kikkawa and E. J. Schelter, Chem. Commun., 2012, 48, 5593-5595; (e) S. K. Langley, N. F. Chilton, B. Moubaraki and K. S. Murray, Chem. Commun., 2013, 49, 6965-6967; (f) X. Yi, K. Bernot, F. Pointillart, G. Poneti, G. Calvez, C. Daiguebonne, O. Guillou and R. Sessoli, Chem.-Eur. J., 2012, 18, 11379-11387; (g) F. Pointillart, Y. Le Gal, S. Golhen, O. Cador and L. Ouahab, Chem.-Eur. J., 2011, 17, 10397-10404; (h) P. H. Lin, T. J. Burchell, R. Clérac and M. Murugesu, Angew. Chem., Int. Ed., 2008, 47, 8848-8851; (i) K. Bernot, F. Pointillart, P. Rosa, M. Etienne, R. Sessoli and D. Gatteschi, Chem. Commun., 2010, 46, 6458-6460; (j) F. Pointillart, K. Bernot, G. Poneti and R. Sessoli, Inorg. Chem., 2012, 51, 12218-12229.

10 Y. L. Wang, B. Gu, Y. Ma, C. Xing, Q. L. Wang, L. C. Li, P. Cheng and D. Z. Liao, CrystEngComm, 2014, 16, 22832289.

11 Y. Liao, W. W. Shum and J. S. Miller, J. Am. Chem. Soc., 2002, 124, 9336-9337.

12 C. Aronica, G. Pilet, G. Chastanet, W. Wernsdorfer, J. F. Jacquot and D. Luneau, Angew. Chem., Int. Ed., 2006, 45, 4659-4662.

13 (a) J. Ruiz, A. J. Mota, A. Rodriguez-Dieguez, S. Titos, J. M. Herrera, E. Ruiz, E. Cremades, J. P. Costes and E. Colacio, Chem. Commun., 2012, 48, 7916-7918; (b) C. E. Burrow, T. J. Burchell, P. H. Lin, F. Habib, W. Wernsdorfer, R. Clérac and M. Murugesu, Inorg. Chem., 2009, 48, 8051-8053; (c) J. C. G. Bünzli and C. Piguet, Chem. Soc. Rev., 2005, 34, 1048-1077; (d) C. Freund, W. Porzio, U. Giovanella, G. Vignali, M. Pasini and S. Destri, Inorg. Chem., 2011, 50, 5417-5429; (e) D. B. A. Raj, B. Francis, M. L. P. Reddy, R. R. Butorac, V. M. Lynch and A. H. Cowley, Inorg. Chem., 2010, 49, 9055-9063; (f) H. Wang, D. Zhang, Z. H. Ni, X. Li, L. Tian and J. Jiang, Inorg. Chem., 2009, 48, 5946-5946; $(g)$ J. An, C. M. Shade, D. A. Chengelis-Czegan, S. Petoud and N. L. Rosi, J. Am. Chem. Soc., 2011, 133, 1220-1223; (h) K. A. White, D. A. Chengelis, K. A. Gogick, J. Stehman, N. L. Rosi and S. Petoud, J. Am. Chem. Soc., 2009, 131, 18069-18071; (i) S. V. Eliseevaa and J. C. G. Bünzli, Chem. Soc. Rev., 2010, 39, 189-227; (j) S. Swavey and R. Swavey, Coord. Chem. Rev., 2009, 253, 2627-2638; (k) K. Binnemans, L. Malykhina, V. S. Mironov, W. Haase, K. Driesen, R. Van Deun, L. Fluyt, C. Görller-Walrand and Y. G. Galyametdinov, ChemPhysChem, 2001, 2, 680-683; $(l)$ J. P. Leonard, P. Jensen, T. McCabe, J. E. O'Brien, R. D. Peacock, P. E. Kruger and T. Gunnlaugsson, J. Am. Chem. Soc., 2007, 129, 10986-10987.

14 (a) Theory and Applications of Molecular Paramagnetism, ed. E. A. Boudreaux and L. N. Mulay, Wiley-Interscience, New York, 1976; (b) G. A. Bain and J. F. Berry, J. Chem. Educ., 2008, 85, 532-536. 
15 Z. Ahmed, W. Ahmed Dar and K. Iftikhar, Inorg. Chim. Acta, 2012, 392, 446-453.

16 (a) G. M. Sheldrick, SHELXS-2014, Program for structure solution, Universität of Göttingen, Germany; (b) G. M. Sheldrick, SHELXL-2014, Program for structure refinement, Universität of Göttingen, Göttingen, Germany, 2014.

17 (a) SHAPE, version 2.0; continuous shape measures calculation; Electronic Structure Group, Universiat de Barcelona, Barcelona, Spain, 2010; (b) H. Zabrodsky, S. Peleg and D. Avnir, J. Am. Chem. Soc., 1992, 114, 7843-7851; (c) M. Pinsky and D. Avnir, Inorg. Chem., 1998, 37, 5575-5582.

18 S. Kanegawa, M. Maeyama, M. Nakano and N. Koga, J. Am. Chem. Soc., 2008, 130, 3079-3094.

19 (a) D. Gatteschi, R. Sessoli and J. Villain, Molecular Nanomagnets, Oxford University Press, New York, 2006, pp. 69-75; (b) J. A. Mydosh, Spin Glasses: An Experimental Introduction, Taylor\&Francis, London, 1993.

20 (a) K. S. Cole and R. H. Cole, J. Chem. Phys., 1941, 9, 341-351; (b) M. Hagiwara, J. Magn. Magn. Mater., 1998, 89, 177-181; (c) T. Kajiwara, M. Nakano, K. Takahashi, S. Takaishi and M. Yamashita, Chem.-Eur. J., 2011, 17, 196-205; (d) S. Dhers, J. P. Costes, P. Guionneau, C. Paulsen, L. Vendier and J. P. Sutter, Chem. Commun., 2015, 51, 7875-7878.
21 (a) X.-J. Zhang, K. Liu, Y.-m. Bing, N. Xu, W. Shi and P. Cheng, Dalton Trans., 2015, 44, 757-7760; (b) T. Li, S. Y. Zhou, X. Li, L. Tian, D. Z. Liao, Z. Y. Liu and J. H. Guo, Dalton Trans., 2016, 45, 3863-3873; (c) M. A. Hareri, E. L. Gavey, J. Regier, Z. R. Ali, L. D. Carlos, R. A. S. Ferreira and M. Pilkington, Chem. Commun., 2016, 52, 11335-11338.

22 (a) J. M. Zadrozny, D. J. Xiao, M. Atanasov, G. J. Long, F. Grandjean, F. Neese and J. R. Long, Nat. Chem., 2013, 5, 577-581; (b) N. Ishikawa, M. Sugita, T. Ishikawa, S. Koshihara and Y. Kaizu, J. Phys. Chem. B, 2004, 108, 11265-11271; (c) C. R. Ganivet, B. Ballesteros, G. de la Torre, J. M. Clemente-Juan, E. Coronado and T. Torres, Chem.-Eur. J., 2013, 19, 1457-1465.

23 (a) I. A. Kahwa, J. Selbin, C. J. O'Connor, J. W. Foise and G. L. McPherson, Inorg. Chim. Acta, 1988, 148, 265-272; (b) J. X. Xu, Y. Ma, D. Z. Liao, G. F. Xu, J. K. Tang, C. Wang, N. Zhou, S. P. Yan, P. Cheng and L. C. Li, Inorg. Chem., 2009, 48, 8890-8896; (c) Y. L. Wang, N. Zhou, Y. Ma, Z. X. Qin, Q. L. Wang, L. C. Li, P. Cheng and D. Z. Liao, CrystEngComm, 2012, 14, 235-239; (d) Y. Ouyang, W. Zhang, N. Xu, G. F. Xu, D. Z. Liao, K. Yoshimura, S. P. Yan and P. Cheng, Inorg. Chem., 2007, 46, 8454-8456; (e) Y. L. Wang, Y. Y. Gao, Y. Ma, Q. L. Wang, L. C. Li and D. Z. Liao, CrystEngComm, 2012, 14, 4706-4712. 